\title{
VITRIFIED HILLFORTS AS ANTHROPOGENIC ANALOGUES FOR NUCLEAR WASTE GLASSES - PROJECT PLANNING AND INITIATION
}

\author{
R. SJÖBLOM ${ }^{1}$, J. WEAVER ${ }^{2,3}$, D. PEELER ${ }^{3}$, J. McCLOY ${ }^{3,4}$, A. A. KRUGER ${ }^{5}$, \\ E. OGENHALL ${ }^{6} \&$ E. HJÄRTHNER-HOLDAR ${ }^{6}$ \\ ${ }^{1}$ Waste Science \& Technology, Luleå University of Technology, Luleå, Sweden / Tekedo AB, Nyköping, Sweden \\ ${ }^{2}$ Department of Chemistry, Washington State University, Pullman, WA, USA \\ ${ }^{3}$ Pacific Northwest National Laboratory, Richland, WA, USA \\ ${ }^{4}$ School of Mechanical and Materials Engineering, Washington State University, Pullman, WA, USA \\ ${ }^{5}$ Department of Energy, Office of River Protection, Richland, WA, USA \\ ${ }^{6}$ The Archaeologists, Geoarchaeological Laboratory, National Historical Museums (SHMM), Uppsala, Sweden
}

\begin{abstract}
Nuclear waste must be deposited in such a manner that it does not cause significant impact on the environment or human health. In some cases, the integrity of the repositories will need to sustain for tens to hundreds of thousands of years. In order to ensure such containment, nuclear waste is frequently converted into a very durable glass. It is fundamentally difficult, however, to assure the validity of such containment based on short-term tests alone. To date, some anthropogenic and natural volcanic glasses have been investigated for this purpose. However, glasses produced by ancient cultures for the purpose of joining rocks in stonewalls have not yet been utilised in spite of the fact that they might offer significant insight into the long-term durability of glasses in natural environments. Therefore, a project is being initiated with the scope of obtaining samples and characterising their environment, as well as to investigate them using a suite of advanced materials characterisation techniques. It will be analysed how the hillfort glasses may have been prepared, and to what extent they have altered under in-situ conditions. The ultimate goals are to obtain a better understanding of the alteration behaviour of nuclear waste glasses and its compositional dependence, and thus to improve and validate models for nuclear waste glass corrosion. The paper deals with project planning and initiation, and also presents some early findings on fusion of amphibolite and on the process for joining the granite stones in the hillfort walls. Keywords: ageing, amphibolite, analogue, anthropogenic, Broborg, glass, hillfort, hill-fort, leaching, long-lived, nuclear, rampart, waste.
\end{abstract}

\section{INTRODUCTION}

Protection of health and habitat implies that the environmental impact of nuclear waste, now as well as in the future, be limited to insignificant or at most tolerable levels. The time scale depends on the longevity of the waste, thus ranging from hundreds to thousands of years for short-lived radioactive waste to tens and hundreds of thousand years for long-lived waste. In the various programmes internationally on waste disposal, this is to be achieved by a combination of features: waste form together with technical and natural barriers. A key question in this regard is how to appropriately design the immobilisation system, including integrated waste form and repository, in order to achieve assurance regarding the intended long-term behaviour. Any such proof will have to rely heavily on natural and anthropogenic analogues [1].

In concordance, a number of countries are stabilising their long-lived waste in a glass matrix, utilising natural and anthropogenic glasses as analogues to prove the long-term 
72 Environmental and Economic Impact on Sustainable Development

durability. Until now, these man-made analogues have included glass in household objects, raw glass ingots, and stained glass windows, but not glass in ancient hillforts where the glass holds pieces of rock together (see below). However, hillfort glasses may offer supplementary or even more similar compositions or other characteristics as compared to glasses utilised as analogues previously. [2] A compositional comparison among different glasses is shown in Fig. 1 [3-9].

\section{OBJECTIVES AND SCOPE}

The prospect of utilisation of a further category of anthropogenic analogues has prompted the United States Department of Energy (US DOE), through its Office of River Protection (ORP), to initiate a project with the purpose to evaluate such possibilities and to apply the results inperformance analyses and environmental impact statements in conjunction with disposal of long-lived radioactive waste.

By necessity, the project will utilise archaeological samples from ancient hillfort sites. Consequently, it has been found pertinent by the US DOE to also include in the objectives to support the understanding of the origin of the samples and their historical context. For instance, there has been a century long debate among historians and archaeologists as to whether the melting of the glass to hold the hillfort rock together was accidental or intentional, and in the latter case whether it was for constructive or destructive purposes $[2,6,10,11]$.

The purpose of the present paper is to present the initiation of the project, including the planning and the first results from sample preparation, information searches and laboratory work.

\section{BACKGROUND}

\subsection{Nuclear waste and nuclear waste glass}

Long-lived radionuclides may be generated by fission as well as neutron activation. Activation of uranium and plutonium in nuclear fuel leads to the creation of transuranic elements which

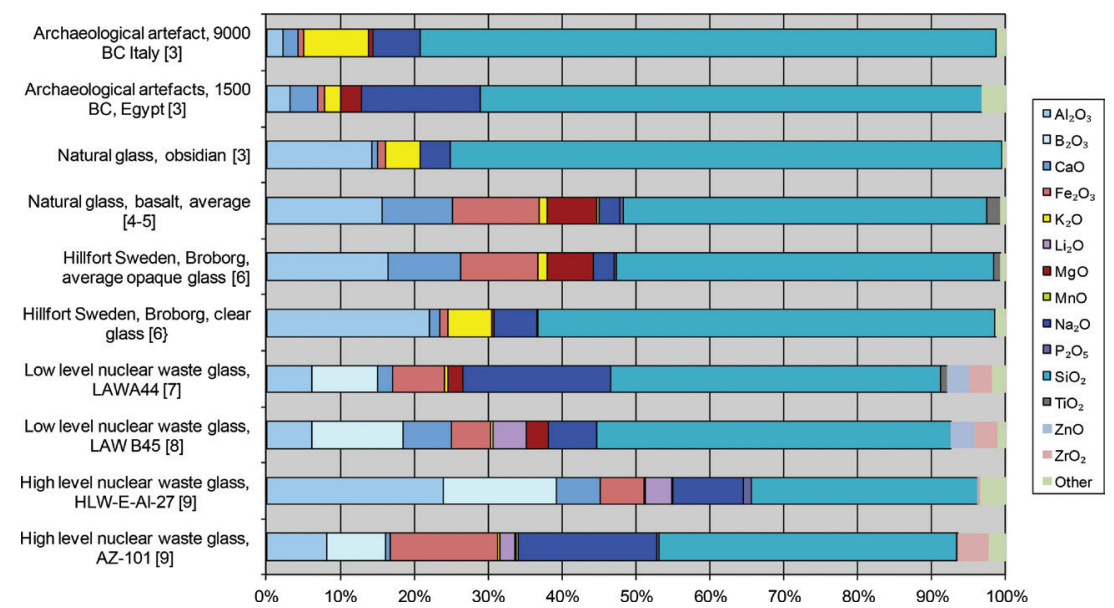

Figure 1: Examples of chemical compositions of glasses figured as oxides. 'Other' is uncertain since some of the iron may be in the form of Fe-II, and since all analyses do not include all elements that may be present. 
in many cases are long-lived. Operational waste at a nuclear power plant is usually shortlived, especially when there is no fuel damage. However, waste from reprocessing of nuclear fuel as well as legacy waste from research and defence is typically long-lived.

It is only long-lived waste that is considered for vitrification. Typically, glass forming chemicals or a pre-fabricated frit is added to the waste to produce a slurry or melter feed. The melter feed is then transferred to the vitrification process, with or without prior evaporation and calcination and is converted to a stable glass product or waste form.

The chemistry of the waste stream might be complex, especially in view of the fact that a wide range of elements are formed during the fission of uranium and plutonium. Glass is often the preferred option for the stabilisation of such fission products since suitable compositions of glass can incorporate most of the elements in an efficient manner.

Such efficiency as well as the long-term stability in various environments have been studied for decades, and much of the work carried out until the year 1992 has been summarised in [12]. A recent summary can be found in [13]. It has been found [14, 15], see also [2], that there may be at least two main mechanisms that control glass corrosion and thus long-term stability, namely alkali extraction and (congruent) matrix dissolution where the former is favoured by low $\mathrm{pH}$-values and the latter by high. There are also differences between the corrosion of high and low silica glasses [16].

\subsection{Hillforts with vitrified walls}

A hillfort is a fortification made of earth and stone, and usually also wood, see Fig. 2 for the example of Broborg in Sweden. They date from around 1000 BC to 1400 AD. [18] It has been assessed [18] that there are up to 30,000 hillforts in Europe. The number of forts with artificially vitrified walls has been estimated to be approximately 200, about half of them in Scotland, and 17 in Sweden [19].

Written contemporary records on hillfort utilisation are scarce, but the sources do tell about sieges and sackings [11]. They also unveil frequent engagements away from hillforts, thus indicating that the forts might actually have been much of a refuge of last resort [11].

Consequently, any understanding of how the vitrification process was performed will have to be based on the artefacts excavated together with various investigations. Thus, archaeologists have lit huge fires to simulate how people might have made the glass, but with little result in terms of vitrification. This has been criticised in view of the contemporary high level of knowledge regarding iron beneficiation and ability to achieve high temperatures by burning charcoal and utilising forced draft [10]. Quality of heat analyses and calculations in [2] regarding wood and charcoal provide further strong support to the conclusions in [10].

\section{PROJECT PLANNING}

\subsection{The present situation}

It is apparent from the previous sections that the objective of utilising ancient glasses as anthropogenic analogues to nuclear waste glasses requires resources from different areas. This refers to the planning of the work as well as its execution.

Consequently, the US DOE through its Office of River Protection has made arrangement for international collaboration in a team of researchers with the following affiliations: US 
74 Environmental and Economic Impact on Sustainable Development

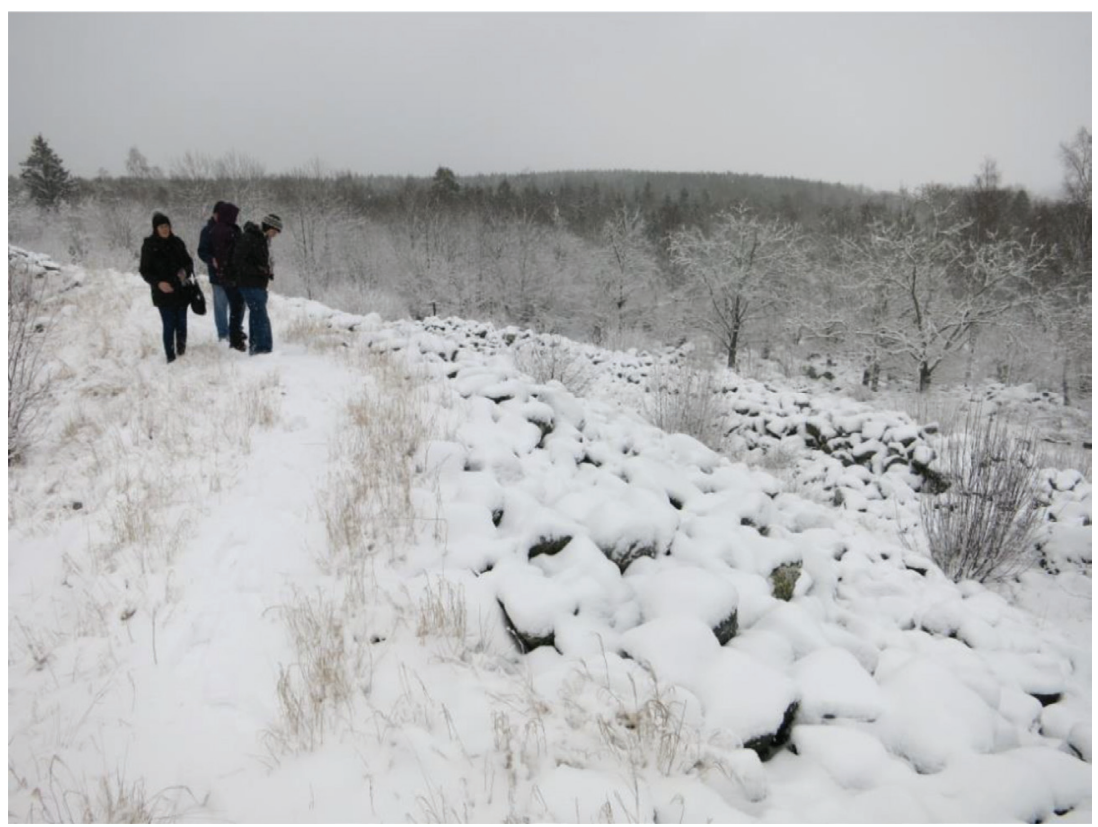

Figure 2: Photograph from the Broborg hillfort outside Uppsala in Sweden showing the rampart consisting of stones joined by vitrified rock.

DOE ORP; Pacific Northwest National Laboratory (PNNL); Washington State University (Department of Chemistry; School of Mechanical and Materials Engineering); Environmental Molecular Sciences.

Laboratory (EMSL), US DOE Office of Biological and Environmental Research; Museum Conservation Institute (part of the Smithsonian Institution); The Archaeologists, Geoarchaeological Laboratory, National Historical Museums (SHMM); Luleå University of Technology / Tekedo AB. Most of the organisations mentioned are based in the United States, but the two latter are in Sweden.

One early DOE ORP programmatic objective has been to get access to authentic sample material (previously excavated), and this has already been achieved through the kind support from Peter Kresten [6, 10, 19] (hillfort samples) and the Geoarchaeological Laboratory (Bloomery furnace samples). Work is in progress at the Archaeologists for the planning of an excavation at Broborg, see Fig. 2, with the purpose of obtaining truly pristine samples.

Work is also in progress at the laboratories in the United States to characterise the authentic (previously excavated) samples thus received, and all participants contribute by searching for and evaluating information. Some examples are provided in Section 5.

\subsection{Some research questions}

Appropriate planning of the work relies heavily on the identification of relevant research questions. Of course, the main question is how to best support comparison between glasses in analogues and waste glasses, including how modelling might be as realistic as possible, and how the results might be validated. 
As already mentioned, information on the genesis of the hillfort samples is valuable for the understanding of the heritage in Sweden and other countries that have hillforts. But the genesis is probably also important for the analogue perspective, and perhaps even for the compositional and other optimisation of the waste glass manufacturing process.

The geochemical environment is another important aspect with respect to long-term durability. The surfaces of the hillfort glasses have been exposed to local soil pore water conditions for millennia, and in the case of Broborg for around 1600 years. Moreover, these conditions may have varied due to land rise and climate changes. Also, the local chemistry is different at a hillfort as compared to that of a site for disposal of nuclear waste.

Related to this question is the one on alterations of the glass surfaces during and after sampling (see Section 5.1). This question is related to that of the mechanisms of alteration of the surfaces on corrosion.

\subsection{Testing programme}

The following testing programme is being contemplated at present. Please note that commitments to certain activities are made from time to time. Sample preparation is in full progress, see Section 5.1.

Data collected from the bulk analyses will be used to develop a deeper understanding of the chemical composition of the glasses, and the surface analyses may provide insight into the chemistry of the alteration layers. Bulk techniques currently underway or under consideration for use are X-ray Tomography (see details below), $\mu$-X-ray fluorescence (elemental composition of the glass), $\mu$-X-ray diffraction (to identify glass vs. crystalline phases), magnetics measurements, and a variety of thermal analyses (to determine water content of the glasses and their alteration phases). X-ray tomography has already been employed in the study of a number of the Broborg samples as it is a non-destructive manner by which to identify preferential sampling sites (Fig. 3, see Section 5.3). Surface characterisation methods may include scanning electron microscopy (SEM) with either energy dispersive spectroscopy (EDS) or wavelength dispersive spectroscopy (WDS). SEM will allow for direct visualisation of possible alteration layers, and EDS or WDS can provide information regarding their chemistry.

\section{EARLY RESULTS}

\subsection{Ongoing work on sample handling and preparation}

Samples taken from the acquired archaeological artefacts are handled and prepared carefully so as to not bias the results of analysis. For this reason, samples are taken without the aid of water or oil cooling during sectioning, and with a new cutting blade. Introduction of water to the sample during preparation is avoided so that water-soluble alteration products are not removed. Use of oil during the sectioning and polishing is also avoided as it would be difficult to remove from the surface and porous interiors of the sample, and could skew any data collected on the carbon content of the alteration layers or exposed surfaces. A new cutting blade is also employed for this reason. When necessary, the samples are polished using a denatured alcohol that has been shown to evaporate without leaving a residue. 
76 Environmental and Economic Impact on Sustainable Development

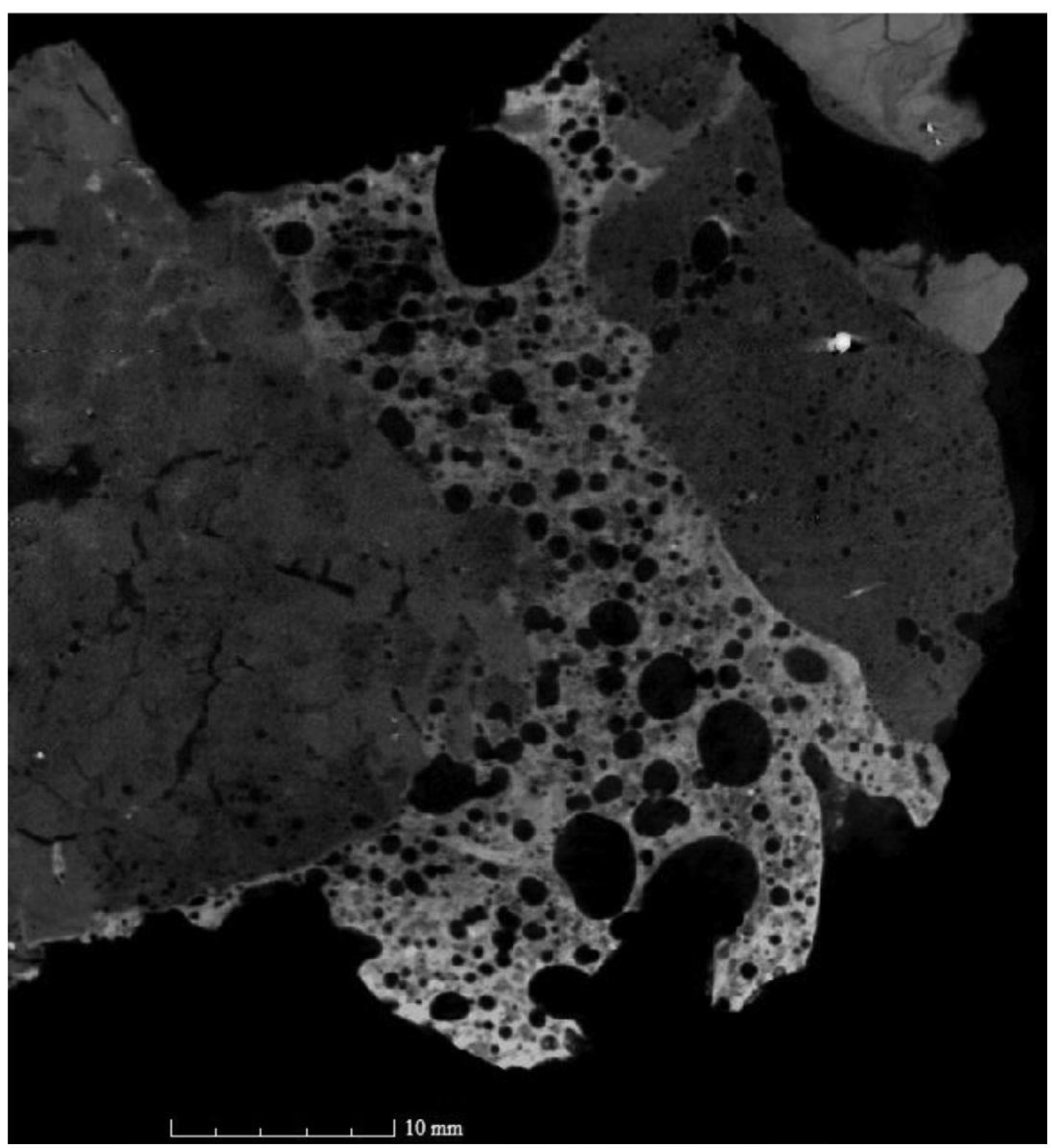

Figure 3: X-ray tomography image of a piece of the Broborg vitrified fort (see Fig. 2). Following the tradition in X-ray imaging, light colour refers to high density, and dark colour to low. Details on how the image was obtained can be found in the appendix.

Areas of artefacts to be sampled are chosen based on the amount of the glass present, their location relative to an external alteration environment, their location relative to an internal alteration environment, and whether that section has been sampled for previous studies. In general, three representative samplings are made: (1) from glass exposed to the external environment (i.e. from the surface of the artefact), (2) from glass open to but not directly exposed to an external environment (i.e. from an open pore at the surface of the artefact), and (3) from an internal environment (i.e. from a close pore). Once the samplings are complete, each one is analysed by bulk and surface sensitive techniques.

\subsection{Information search on amphibolite and its thermal behaviour}

One of the first findings in the present project has been that a synthetic mixture of the constituents (except hydrogen) of the Broborg glass (see Fig. 1), requires temperatures exceeding 
$1400^{\circ} \mathrm{C}$ in order to melt. Additionally, since the ancient people probably had no possibility to achieve such a high temperature even with charcoal and forced access of air [13], some other factors must have been involved.

Earlier, Kresten \& Ambrosiani [6] had found that Broborg glass melted differently under oxidising (air) and inert (nitrogen) conditions. In the former case, melting started at around $1130^{\circ} \mathrm{C}$ whilst it started already at $1075^{\circ} \mathrm{C}$ in the latter. Moreover, visual inspection of the samples clearly indicates that the melting is associated with a substantial evolution of gas phase. Obviously, the vitrification process is considerably more complex than just melting. This observation has prompted an information search and the results are presented in the following.

Kresten \& Ambrosiani [6] had observed that the rock that melted was primarily amphibolite. This is a type of rock that is present only occasionally, and actually had to be collected by the ancient people to serve in the ramparts which were erected using mainly gneissic granite.

Amphibole has been described [20] as the 'garbage can' or 'waste basket' in mineralogy since its chemical composition shows very wide variations. Amphibolites are often formed from dolerite (British English, diabase in the US) as well as from basalt, and gabbro, which all have similar chemical compositions (see Fig. 1 for basalt). It should be observed, however, that amphibolites are formed only under certain conditions: typically at pressures around $0.3-1.2 \mathrm{GPa}$ and temperatures around $550^{\circ} \mathrm{C}-750^{\circ} \mathrm{C}$, see e.g. Figure 3.19 in [4], and in the presence of water at lithostatic pressure. Amphibolites that reach the surface through orogenic (uplift) processes are thus only thermodynamically metastable. At a few hundred degree Celsius, ion mobility starts to become significant [21], and consequently also various reactions may take place such as oxidation, dehydroxylation and incongruent recrystallisation.

Most of the work on amphibolites has been carried out at high pressures and moderately high temperatures and are thus not of primary concern for the present work. However, Ghose [21], and references therein, describe a case when crocidolite, $\mathrm{Na}_{2} \mathrm{Fe}_{2}{ }^{3+} \mathrm{Fe}_{2,6}{ }^{2+} \mathrm{Mg}_{0.4} \mathrm{SiO}_{22}(\mathrm{OH})_{2}$, was heated in nitrogen or argon, and in oxygen or air, respectively. For inert atmosphere, dehydroxylation took place at around $500^{\circ} \mathrm{C}-700^{\circ} \mathrm{C}$, and at about $800^{\circ} \mathrm{C}$, the anhydride decomposed endothermally into acmite, cristobalite, spinel and a liquid. By contrast, in an oxidising atmosphere, hydrogen ions and electrons were lost already at $300^{\circ} \mathrm{C}-450^{\circ} \mathrm{C}$ to yield oxyamphibole with the formula $\mathrm{Na}_{2} \mathrm{Fe}_{4}{ }^{3}+\mathrm{Fe}_{0,6}{ }^{2+} \mathrm{Mg}_{0,4} \mathrm{Si}_{8} \mathrm{O}_{22}(\mathrm{OH})_{2}$. This compound decomposed at $600^{\circ} \mathrm{C}-950^{\circ} \mathrm{C}$ to yield acmite, hematite, cristobalite and spinel.

It should be noted that the chemical composition of crocidolite deviates substantially from that of Broborg glass in Fig. 1. Nonetheless, the example shows that differences in behaviour are to be expected depending on the atmosphere and that much information can be obtained by thermal analysis and related techniques. Incidentally, formation of spinel on heating of Broborg amphibolite was confirmed in [6].

Nonetheless, it appears that the $\mathrm{Fe}^{2+} / \mathrm{Fe}^{3+}$ ratio [22] as well as the content of water [23, 24] (or hydroxide) may have a profound effect in that they lower the viscosity of a glass melt.

\subsection{Imaging}

A lot of observations can be made using the naked eye or an inexpensive optical microscope. A drawback in this regard is that only a part of the rock surface will be in focus, wherefore photographs may not be very illuminating in an article. Nonetheless, such observations have been made, and the results are as follows. 
78 Environmental and Economic Impact on Sustainable Development

Unheated Broborg amphibolite surface has a microcrystalline structure with typical sizes of the crystallites around $0.01 \mathrm{~mm}$. The structures are slightly layered. Heated or (partially) melted amphibolite has less of a crystalline surface structure. Moreover, layers may have separated to form pores and fissures, and there is also evidence of expansion of the partially melted material.

The best visual illustration of the structure of the rock being held together by a glass in a vitrified fort may well be what might be obtained using X-ray tomography, and such an image is presented in Fig. 3. See the appendix for details. The image shows a bubble-filled phase with glass density higher than the surrounding rock (brighter contrast) affixing two pieces of a different rock type which appear also to have seen high temperatures due to some dark areas suggesting phase separation as well as outgassing. It is believed the bubble-filled phase is due to the amphibolite and the rocks being held together are a gneissic granite. Work is in progress to confirm these assertions.

\section{DISCUSSION AND CONCLUSIONS WITH REGARD TO THE EARLY RESULTS}

It is obvious from the results of the information search, as well as of the tests on melting of synthetic material, that the melting of amphibolite at Broborg is a quite complex process which probably is dependent on the redox conditions as well as the water content in the furnace atmosphere.

Depending on the details of the process used, the atmosphere in a charcoal fire may be reducing or oxidising. If reducing, it may or may not contain water. In the case of a moist reducing atmosphere, water may react with charcoal such that hydrogen is being formed. Water may have the capability to oxidise iron to at least $\mathrm{Fe}_{3} \mathrm{O}_{4}$, but hydrogen might reduce it all the way to elementary iron. The information search indicates that reduction of iron and presence of water may facilitate the liquefaction.

Thus, the quality of heat analysis in [2] is probably very relevant for the process of joining the stones, but does not constitute a full explanation. Details on the redox and water vapour conditions are also likely to be highly important.

Obviously, gas is released from amphibolite when it is in a partially molten condition. This, as well as the imaging, confirms the following description by Kresten and Ambrosiani [6]: "The gas-charged melt penetrated the space between the gneiss boulders, invaded all open fractures in the fire-cracked rock, and served as a flux to initiate melting of the gneiss, thus firmly cementing the whole vitrified mass."

\section{ACKNOWLEDGEMENTS}

The authors wish to thank Professor Peter Kresten for sharing his knowledge and for consenting to part from a large fraction of his samples that had been collected during many years of work. The authors also wish to recognize the work by Dr. TamasVarga and Adriana Lynell McKinney, Pacific Northwest National Laboratory, on obtaining the x-ray tomography image, see the appendix for further detail.

The project has been financed by US DOE Environmental Management International Programs through its Office of River Protection.

\section{REFERENCES}

[1] Sjöblom, R., Lindskog, S. \& Andreas, L., Long term aspects of landfilling and surface disposal - lessons learned from nuclear and non-nuclear decommissioning, remediation and waste management. Journal of Earth Sciences and Geotechnical Engineering, 3(3), pp. 35-51, 2013. 
[2] Sjöblom, R., Ecke, H. \& Brännvall, E., Vitrified forts as anthropogenic analogues for assessment of long-term stability of vitrified waste in natural environments. International Journalof Sustainable Development and Planning, 8(3), pp. 380-399, 2013. http://dx.doi.org/10.2495/SDP-V8-N3-380-399

[3] Le Bourhis, E., Glass., Mechanics and Technology, Wiley-VCHVerlag GmbH \& Co, 2008.

[4] Dobran, F., Volcanic Processes, Mechanisms in Material Transport, Kluwer Academic, 2001.

[5] Le Maitre, R.W., The chemical variability of some common igneous rocks. Journal of Petrology, 17, pp. 589-637, 1976. http://dx.doi.org/10.1093/petrology/17.4.589

[6] Kresten, P. \& Ambrosiani, B., Swedish vitrified forts - a reconnaissance study. Fornvännen, 87, pp. 1-17, 1992.

[7] Pierce, E.M., Rodriguez, E.A., Calligan, L.J., Shaw, W.J. \& McGrail, B.P., An experimental study of the dissolution rates of simulated aluminoborosilicate waste glasses as a function of $\mathrm{pH}$ and temperature under dilute conditions. Applied Geochemistry, 23(9), pp. 2559-2573, 2008. http://dx.doi.org/10.1016/j.apgeochem.2008.05.006

[8] Joseph, I., Bowan II, B.W., Gan, H., Kot, W.K., Matlack, K.S., Pegg, I.L. \& Kruger, A.A., High Aluminum HLW Glasses for Hanford's WTP, Waste Management Symposium: Phoenix, Arizona, 2010.

[9] Matyáš, J., Lang, J.B., Huckleberry, A.R. Owen, A.T., Rodriguez, C.P. \& Kruger, A.A., HLWglass studies: development of crystal-tolerant HLWglasses. Pacific Northwest National Laboratory, Report PNNL-21308, 2012. Prepared for United States Department of Energy under the contract DE-AC05-76RL01830.

[10] Kresten, P., Kero, L. \& Chyssler, J., Geology of the vitrified hill-fort Broborg in Uppland, Sweden. Geologiska Föreningen i Stockholm Förhandlingar, 115, pp. 13-24, 1993. http://dx.doi.org/10.1080/11035899309454825

[11] Harding, D., Iron Age Hillforts in Britain and Beyond, Oxford University Press, 2012.

[12] Clark, D.E. \& Zoitos, B.K.(eds), Corrosion of Glass, Ceramics and Ceramic Superconductors. Principles, Testing, Characterization and Applications, Noyes Publications: Park Ridge, New Jersey, USA, 1992.

[13] Weaver, J.L., McCloy, J.S., Ryan, J.V. \& Kruger, A.A., Ensuring longevity: Ancient glasses help predict durability of vitrified nuclear waste. American Ceramic Society Bulletin, 95(4), pp. 18-23, 2016.

[14] Handbook, Vitrification technologies for treatment of hazardous and radioactive waste. U. S, Environmental Protection Agency, EPS/625/R-92/002, 1992.

[15] Grambow, B., Geochemical approach to glass dissolution. In Corrosion of Glass, Ceramics and Ceramic Superconductors, Noyes Publications: Park Ridge, New Jersey, USA, 1992.

[16] Jantzen, C.M., Thermodynamic approach to glass corrosion. In Corrosion of Glass, Ceramics and Ceramic Superconductors, Noyes Publications: Park Ridge, New Jersey, USA, 1992.

[17] Jercinovic, M.J. \& Ewing,R.C., Corrosion of geological and archaeological glasses. In Corrosion of Glass, Ceramics and Ceramic Superconductors, Noyes Publications: Park Ridge, New Jersey, USA, 1992.

[18] Ralston, I., Celtic Fortifications, Tempus Publishing Ltd: Stroud, UK, 2000. 
80 Environmental and Economic Impact on Sustainable Development

[19] Kresten, P., The vitrified forts of Europe: saga, archaeology and geology. In Applied Mineralogy: Developments in Science and Technology, Proceedings of the 8 International Congress on Applied Mineralogy (ICAM 2004). eds. M. Pecchio, F.R. Dias de Andrade, L.Z.D'Agostino, H. Kahn, L.M.Sant'Agostino \& M.M.M. LéTassinari,Sao Paolo, pp. 355-357, 2004.

[20] Robinson, P., Spear, F.S., Schumacher, J.C., Klein, J.L.C., Evans, B.W. \& Doolan, B.L., Phase relations of metamorphic amphiboles: natural occurrence and theory. In Amphiboles: Petrology and Experimental Phase Relations. Reviews in Mineralogy, eds. D.R. Veblen \& P.H. Ribbe, 9B, pp. 1-42,1982.

[21] Ghose, S., Subsolidus reactions and microstructures in amphiboles.In Amphiboles and Other Hydrous Pyriboles-mineralogy, Reviews in Mineralogy, ed. D.R. Veblen, 9A, pp. 325-337, 1985.

[22] Dingwell, D.B. \& Virgo, D., The effect of oxidation state on the viscosity of melts in the system $\mathrm{Na}_{2} \mathrm{O}-\mathrm{FeO}-\mathrm{Fe}_{2} \mathrm{O}_{3}-\mathrm{SiO}_{2}$. Geochimicaet Cosmochimica Acta, 51, pp. 195-205, 1987.

[23] Morizet, Y., Nichols, A.R.L., Kohn, S.C., Brooker, R.A. \& Dingwell, D.B., The influence of $\mathrm{H}_{2} \mathrm{O}$ and $\mathrm{CO}_{2}$ on the glass transition temperature: insights into the effects of volatiles on magma viscosity. European Journal of Mineralogy, 19, pp. 657-669, 2007. http://dx.doi.org/10.1127/0935-1221/2007/0019-1751

[24] Robert, G., Whittington, A.G., Stechern, A. \& Behrens, H., The effect of water on the viscosity of a synthetic calc-alkaline basaltic andesite. Chemical Geology, 346, pp. 135-148, 2013.

http://dx.doi.org/10.1016/j.chemgeo.2012.10.004

\section{APPENDIX. THE X-RAY TOMOGRAPHY IMAGE}

$\mathrm{X}$-ray computed tomography was used to visualise the internal microstructure of the glass. The specimen was scanned with an X-Tek/Metris XTH 320/225 kV high-resolution microfocus tomography (XCT) scanner (Nikon Metrology, Brighton, MI) at $95 \mathrm{kV}$ and $170 \mu \mathrm{A} \mathrm{x}$-ray power for optimum image quality and contrast. The samples were rotated continuously during the scans with momentary stops to collect each projection (shuttling mode) to minimise ring artefacts. 3142 projections were collected over 360 degrees with 708 millisecond exposure time and 4 frame per projection. Image voxel size was 65 micrometers. The images were reconstructed to get a three-dimensional dataset using CT Pro 3D (Metris XT 2.2, Nikon Metrology). The representative 3D rendering was created using the visualization program VG Sudio Max 2.1 (Volume Graphics GmbH, Germany).

The research was performed using EMSL, a DOE Office of Science User Facility sponsored by the Office of Biological and Environmental Research and located at Pacific Northwest National Laboratory under proposal number 49141. The image was provided by Dr. TamasVarga and Adriana Lynell McKinney (Pacific Northwest National Laboratory).

The image is included as Fig. 3 in the report. 